\title{
Genetic counselling: the psychological impact of meeting patients' expectations
}

\author{
Susan Michie, Theresa M Marteau, Martin Bobrow
}

\begin{abstract}
We know little about patients' expectations of genetic counselling, the extent to which these are met, and whether meeting expectations is associated with improved patient outcome. This study describes 131 consultations of patients referred to a regional genetics centre, and documents their expectations, the extent to which these are met, and the predictors and consequences of expectations being met. The outcomes assessed were state anxiety, concern about the problem for which the patient was referred, and satisfaction with information given.
\end{abstract}

Patients came to genetic counselling expecting information (79\%), explanation $(63 \%)$, reassurance $(50 \%)$, advice $(50 \%)$, and help in making decisions (30\%). The majority got what they were expecting: $\mathbf{7 4 \%}$ had their expectation for information met, $56 \%$ had their expectation for explanation met, $60 \%$ had their expectation for reassurance met, $61 \%$ had their expectation for advice met, and $73 \%$ had their expectation for help with making decisions met. Patient expectations, and whether or not these were met, were not predicted by any of the patient or counsellor variables measured.

When patients' expectations for reassurance and advice were met, patients were less concerned and their anxiety level was more reduced than when such expectations were not met. Meeting patients' expectations for information, explanation, or help with decision making were not associated with better outcomes. Explanations for these results and implications for the practice of genetic counselling are discussed.

(F Med Genet 1997;34:237-241)

Keywords: genetic counselling; patient expectations; patient anxiety.

With the rapid rate of developments in human genetics and their clinical application, the demand for genetic counselling is increasing. The following widely quoted definition of genetic counselling illustrates what genetic counsellors think they should provide: “... a communication process which deals with the human problems associated with the occurrence, or risk of occurrence, of a genetic disorder in a family. This process involves an attempt by one or more appropriately trained persons to help the individual person or the family to (1) comprehend the medical facts, including the diagnosis, the probable course of the disorder and the available management; (2) appreciate the way heredity contributes to the disorder and the risk of recurrence in specified relatives; (3) understand the options for dealing with the risk of recurrence; (4) choose the course of action which seems appropriate to them in view of their risk and their family goals and act in accordance with that decision; and (5) make the best possible adjustment to the disorder in an affected family member or to the risk of recurrence of that disorder or both".

We know little, however, about the extent to which this coincides with what occurs in genetic counselling or with what patients want from genetic counselling. The little research that has been done on the process of genetic counselling has found that the most frequent type of interaction is that in which the counsellor gives factual information. ${ }^{23}$ The amount of time spent dealing with psychological or social issues appears to be minimal. ${ }^{4}$ In an ethnography of genetic counselling, Bosk ${ }^{5}$ noted that while more recent statements of the aims of genetic counselling encompass dealing with emotions, ${ }^{6}$ the practice of genetic counselling has yet to encompass this.

Research in the areas of both consumer and health care satisfaction has found that it is the interaction between expectations and subsequent experience that leads to satisfaction or dissatisfaction. ${ }^{7-9}$ We know that in several areas of medicine, doctors do not always meet patient expectations. A study of 73 general practice consultations found that patients presented emotional and social agendas to a far greater degree than doctors addressed these concerns. ${ }^{10}$ An analysis of 800 paediatric outpatient consultations found that $24 \%$ of mothers were dissatisfied with the consultation. The most frequent complaint was that the doctor had shown insufficient interest in the mother's concerns. ${ }^{11}$ Recordings of the consultations showed that this was the case in the great majority of consultations, with the doctors discussing solely the technical aspects of the child's condition, paying little or no attention to the mother's feelings.

Eliciting and addressing patient concerns is associated with better patient outcome in general practice. Those patients of doctors who had responded to the patient in such a way as to allow the patient to express all of his or her reasons for coming, including expectations, had their concerns resolved to a greater extent than patients of less patient centred doctors. ${ }^{12}$
Received 28 June 1996 Revised version accepted for publication 1 November 1996 
Among oncology inpatients, an association has been found between expectations being met and patient satisfaction. ${ }^{13}$ The strongest predictor of satisfaction with doctors' behaviour among this group was the patient's perception of needs being met. It should be noted that these were prospective follow up, rather than experimental, studies so that conclusions about causation cannot be drawn.

We do not know whether patient expectations, and the extent to which these are met, are associated with patient outcomes in genetic counselling. A six month follow up of genetic counselling suggested that patients did not always get what they wanted from genetic counselling. ${ }^{4}$ Of the 164 patients who were interviewed six months later and said they wanted more genetic counselling, $24 \%$ said this was because the counsellor had not answered all their questions or they had not understood the information given and $23 \%$ said they had not asked all their questions.

Since contact with genetic counsellors is much less common than contact with general practitioners, patients are less likely to have clear ideas about what to expect from genetic counselling than about what to expect when they attend for a GP appointment. Genetic counselling patients do, however, have reasons for coming to genetic counselling appointments. ${ }^{4}$ The current study therefore examined expectations of the consultation by asking what patients were hoping for. The aim of the study is to describe what patients are expecting from an initial genetic counselling consultation, the extent to which these expectations are met, the factors that predict this, and whether the meeting of expectations affects patient outcomes.

\section{Methods}

THE STUDY SAMPLE

Those eligible for the study were patients attending their first genetic counselling consultation. The sample was a consecutive cohort of patients referred for genetic counselling. Patients were excluded if they had come for a predetermined series of consultations (in the study clinic, this is limited to patients at risk for Huntington's disease), if they had come for an emergency appointment, or if their knowledge of the English language was not sufficient to answer the questions.

In a nine month period, 182 patients were approached for inclusion in the study. Of these, 18 declined to take part in the study, 25 were withdrawn because of technical problems in tape recording the consultations, and eight were withdrawn because they did not return a questionnaire following the consultation.

The study sample comprised 131 patients. There were no differences in any of the demographic variables between those included and those excluded. The sample comprised 108 women and 23 men (mean age 32 years, SD 7) and 122 described their ethnic group as white. Eighty-seven were employed, and 104 were living with their partner. Those affected were the participant or partner in 29 cases, a child or fetus in 54, a parent in 31 , a sib in 26 , and a member of the extended family in 45 . Conditions, when known, were categorised as multifactorial (22), chromosomal (21), autosomal recessive (20), autosomal dominant with $100 \%$ penetrance (10), autosomal dominant with $<100 \%$ penetrance (13), $\mathrm{X}$ linked recessive (2), and non-genetic (3). In 59 cases the diagnosis was known, in 51 it was suspected but further investigations were planned, in five it was suspected but no further investigations were planned, and in 16 the data were missing.

For the great majority of patients, the studied consultation was their only consultation. They had not received any preclinic contact by home visit or telephone. Six months after their consultation, $86 \%$ of the 94 contacted said that they had not been back to the genetics department, $8 \%$ had returned to receive test results, $4 \%$ for a follow up appointment, and $2 \%$ to get additional information.

Patients were seen by 11 counsellors: six clinical geneticists and five genetic nurse counsellors working in a regional genetics centre.

\section{DESIGN}

In this prospective descriptive study, patients were interviewed briefly before their consultations in the clinic while waiting for their appointment. They were interviewed twice after counselling: one to two weeks, and six months later. They were interviewed by telephone $(n=120)$ or sent a postal questionnaire if they did not have a telephone $(n=11)$.

\section{MEASURES}

\section{Nature of the referral problem}

Information was gathered from the referral letter about who in the family was affected with the condition; whether a formal diagnosis of the condition and its cause had been identified; and whether the problem involved a recent death, miscarriage, or termination of pregnancy.

\section{Patient: preconsultation}

Personal information included age, gender, ethnic status, educational level, current employment, and marital status.

To discover their expectations, patients were asked what they were hoping to get out of the consultation, using a question with six response options developed as a result of earlier piloting: information, explanation, reassurance, advice, help in making decisions, and anything else. The reason that patients were asked about what they were hoping for, rather than what they were expecting, was that patients who had not had previous experience of genetic services may not have known what to expect.

Level of concern about the issue that brought them to the consultation was assessed using a seven point scale anchored by "not at all" and "extremely".

State anxiety was measured using the six item short form state scale of the Spielberger State-Trait Anxiety Inventory ${ }^{14}$; trait anxiety was measured using the 20 item trait scale. ${ }^{15}$ 


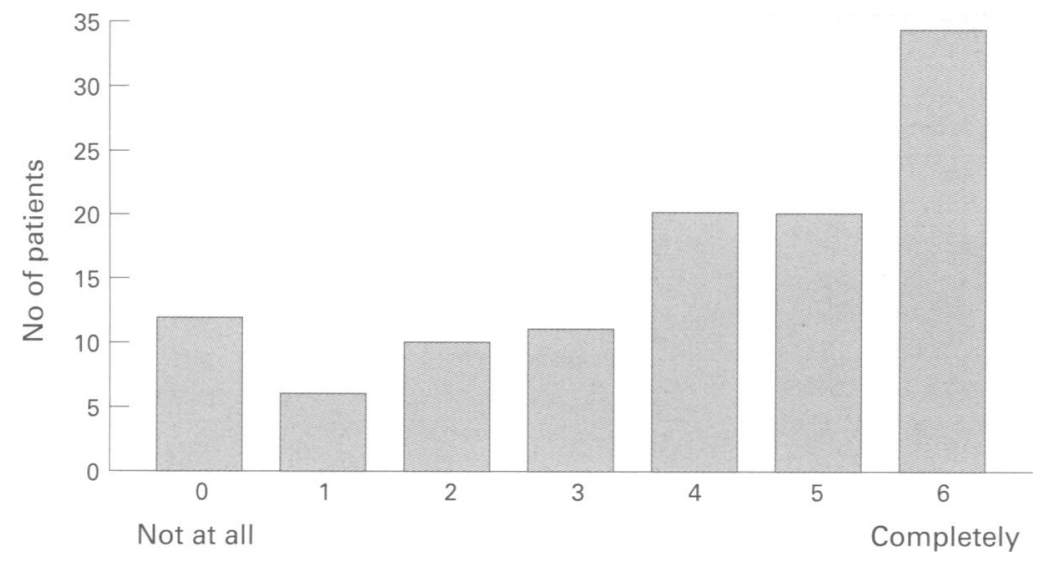

Figure 1 The extent to which patients got what they were expecting from the consultation.

\section{Patient: postconsultation}

To discover if their expectations had been met, patients were also asked what they had got out of the consultation with the same response options above. They were also asked the extent to which the main hope they had identified before the consultation was met, using a seven point scale anchored by "not at all" and "extremely".

Level of concern about the issue that brought them to the consultation was assessed using a seven point scale anchored by "not at all" and "extremely".

Satisfaction with information was assessed using a factor derived by factor analysis from ratings on seven point scales of usefulness of information, usefulness of explanation, and a general rating of the consultation from "poor" to "excellent". The factor had an Eigenvalue of 2.57 and a Cronbach's alpha of 0.83 , showing that it accounted for a reasonably large proportion of the variance and satisfactory internal reliability.

State anxiety was measured using the six item short form state scale of the Spielberger State-Trait Anxiety Inventory ${ }^{14}$; trait anxiety was measured using the 20 item trait scale. ${ }^{15}$

Inter-rater reliability of the codes for the open ended questions was examined using the kappa reliability statistic for 15 cases. A score of between 0.4 and 1.0 was obtained for all categories where a kappa statistic could be generated. Where the statistic could not be generated, the proportional agreement was measured and reliability found to be acceptable. ${ }^{16}$

\section{Counsellor}

Personal information included years of experience in genetic counselling, whether the counsellor was a nurse or doctor, and whether the counsellor had undergone training in counselling.

\section{PROCEDURE}

Participating patients were given a questionnaire to complete in the waiting room before their consultation. They were told that they would be interviewed by telephone on two occasions, 10 days and six months after the consultation, and information about the most convenient times for telephoning was sought. The telephone interviews were tape recorded.
Table 1 Patients' expectations from the consultation (patients could tick more than one option) $(n=131)$

\begin{tabular}{lll}
\hline & No & $\%$ \\
\hline Information & 104 & 79 \\
Explanation & 82 & 63 \\
Advice & 65 & 50 \\
Reassurance & 65 & 50 \\
Help in making decisions & 40 & 30 \\
Anything else & 5 & 4 \\
\hline
\end{tabular}

For the 11 patients with no telephone this interview was sent as a questionnaire by post. Counsellors were asked to complete their questionnaires just once, when the study started.

ANALYSIS

The association between the meeting of patient expectations and patient outcomes was tested by one way analyses of variance. The comparison of each outcome was across four groups: for each expectation, whether it was expected and received, not expected and received, not expected and not received, and expected and not received. Predictors of expectation and of whether or not expectations were met were examined using discriminant function analyses. Where there are missing data, the denominator was less than 131

\section{Results}

BEFORE THE CONSULTATION: EXPECTATIONS The results of asking patients about their expectations are shown in table 1.

AFTER THE CONSULTATION: EXPECTATIONS MET The majority of patients chose the positive end of the rating scale to describe the extent to which their expectations had been met, although 12 patients said they had been met "not at all". The results are shown in fig 1 (there are missing data in 18 cases).

Thirty-three percent $(42 / 127)$ said there was at least one thing they would have liked from the consultation but did not get. Fifteen percent (19) said they would have liked more information, $11 \%$ (4) wanted answers to questions, $5 \%$ (6) a blood test, $4 \%$ (5) more certainty, 3\% (4) reassurance, 3\% (4) explanation, $2 \%$ (3) sensitivity, 25 (2) test results, and $1 \%$ (1) advice.

Patients' specific expectations of the consultation and what they got out of it are shown in table 2 . The percentages of those whose expectations were met (either by getting something they were expecting or by not getting something they were not expecting) were $74 \%$ (97/130) for information, 56\% (73/131) for explanation, $60 \%(78 / 131)$ for reassurance, $61 \%(80 / 131)$ for advice, and $73 \%(94 / 131)$ for help with making decisions. The percentage of patients who did not get something they were expecting ranged from $11 \%(15 / 130)$ in the case of information to $26 \%(34 / 131)$ in the case of advice.

PREDICTORS OF EXPECTATIONS AND OF THE MEETING OF EXPECTATIONS

The type of expectations patients had of the consultation were not predicted by any of the patient measures nor by the nature of the 
Table 2 Patients' reports of their expectations before the consultation and what they received from the consultation $(n=131)$

\begin{tabular}{llll}
\hline & & Received & Not received \\
\hline Information & Expected & 90 & 15 \\
& Not expected & 19 & 7 \\
Explanation & Expected & 52 & 30 \\
& Not expected & 28 & 21 \\
Reassurance & Expected & 40 & 25 \\
Advice & Not expected & 28 & 38 \\
Help in making & Expected & 31 & 34 \\
decisions & Not expected & 17 & 49 \\
& Expected & 13 & 27 \\
& Not expected & 10 & 81 \\
\hline
\end{tabular}

Table 3 Mean scores of outcome measures according to whether or not reassurance was expected and received (mean (SD))

\begin{tabular}{|c|c|c|c|c|c|c|c|}
\hline & $\begin{array}{l}\text { Expected/ } \\
\text { received }\end{array}$ & $\begin{array}{l}\text { Not } \\
\text { expected } \\
\text { received }\end{array}$ & & $\begin{array}{l}\text { Not } \\
\text { expected } \\
\text { not } \\
\text { received }\end{array}$ & & $\begin{array}{l}\text { Expected/ } \\
\text { not } \\
\text { received }\end{array}$ & \\
\hline Anxiety & 33.33 & 36.67 & & 35.68 & & 32.27 & \\
\hline $\begin{array}{l}\text { Change in } \\
\text { anxiety } \\
\text { (pre/post } \\
\text { consultation) }\end{array}$ & $11.84 \mathrm{a}$ & 5.23 & b & 3.53 & c & $7.20 \mathrm{~d}$ & * \\
\hline Concern & 2.80 & 3.32 & f & 3.58 & g & 3.76 & $\star$ \\
\hline $\begin{array}{l}\text { Change in } \\
\text { concern } \\
\text { (pre/post } \\
\text { consultation) }\end{array}$ & $2.22 \mathrm{i}$ & 1.47 & j & 0.95 & $\mathrm{k}$ & $0.92 \quad 1$ & $\star \star$ \\
\hline $\begin{array}{l}\text { Satisfaction } \\
\text { with } \\
\text { information }\end{array}$ & 14.67 & 15.00 & & 13.87 & & 14.85 & \\
\hline
\end{tabular}

ANOVA: ${ }^{\star} \mathrm{p}<0.05$. Significant differences: $a \& b, a \& c, e \& g, e \& h$ ${ }^{\star \star} \mathrm{p}<0.01$. Significant differences: $i \& k, i \& l$.

problem. Whether or not their expectations were met were not predicted by any of the patient, counsellor, or problem variables (see Measures section).

CONSEQUENCES OF NOT MEETING EXPECTATIONS Patients who expected and received reassurance experienced a greater reduction in anxiety than those who did not expect it $(F(3,125)=3.45, p=0.02)$. They were also less concerned, and showed a greater decrease in concern $(\mathrm{F}(3,125)=2.77, \mathrm{p}=0.044$ and 4.92 , $\mathrm{p}=0.003$ respectively), than those who did not receive reassurance (table 3 ).

Patients who expected and received advice experienced a greater reduction in anxiety than those who did not get advice $(F(3,125)=3.25$, $\mathrm{p}=0.02)$. Getting advice when it was not expected was associated with a greater decrease in anxiety than not getting advice when it was expected (table 4 ).

Having expectations for information met was not associated with emotional outcomes, but was associated with satisfaction with information $(F(3,95)=3.96, p=0.01)$. As shown in table 5, the association was not a straightforward one.

\section{Discussion}

Patients came to genetic counselling expecting information $(79 \%)$, explanation $(63 \%)$, reassurance $(50 \%)$, advice $(50 \%)$, and help in making decisions $(30 \%)$. While the majority got what they were expecting, a sizeable minority did not: $74 \%$ had their expectation of information met, $56 \%$ had their expectation of
Table 4 Mean scores of outcome measures according to whether or not advice was expected and received

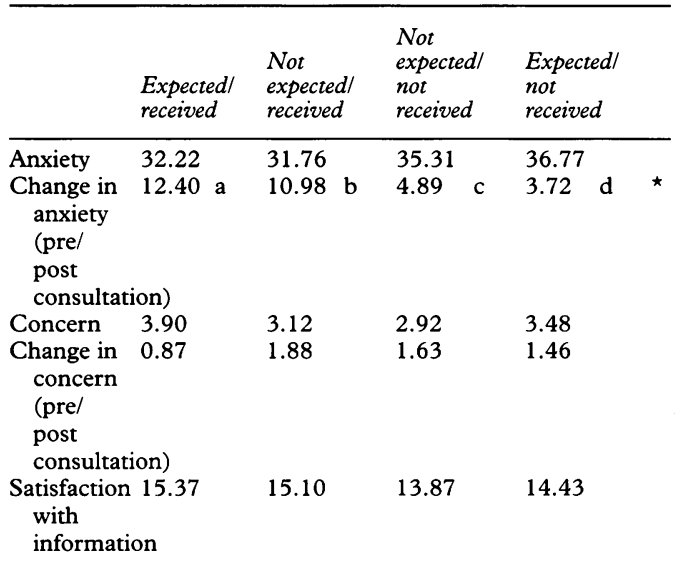

ANOVA: ${ }^{\star} \mathrm{p}<0.05$. Significant differences: $\mathrm{a} \& \mathrm{c}, \mathrm{a} \& \mathrm{~d}, \mathrm{~b} \& \mathrm{~d}$.

Table 5 Mean scores of outcome measures according to whether or not information was expected and received

\begin{tabular}{|c|c|c|c|c|c|}
\hline & $\begin{array}{l}\text { Expected/ } \\
\text { received }\end{array}$ & $\begin{array}{l}\text { Not } \\
\text { expected/ } \\
\text { received }\end{array}$ & $\begin{array}{l}\text { Not } \\
\text { expected/ } \\
\text { not } \\
\text { received }\end{array}$ & $\begin{array}{l}\text { Expected/ } \\
\text { not } \\
\text { received }\end{array}$ & \\
\hline Anxiety & 33.79 & 31.4 & 37.14 & 42.14 & \\
\hline $\begin{array}{l}\text { Change in } \\
\text { anxiety } \\
\text { (pre/ } \\
\text { post } \\
\text { consultat }\end{array}$ & ion) & 6.50 & 2.86 & 3.64 & \\
\hline Concern & 3.27 & 4.00 & 2.71 & 3.07 & \\
\hline $\begin{array}{l}\text { Change in } \\
\text { concern } \\
\text { (pre/ } \\
\text { post } \\
\text { consultat }\end{array}$ & ion) & 1.00 & 1.58 & 2.06 & \\
\hline $\begin{array}{l}\text { Satisfaction } \\
\text { with } \\
\text { informat }\end{array}$ & $14.41 \mathrm{a}$ & $15.53 \mathrm{~b}$ & $10.75 \mathrm{c}$ & $17.50 \mathrm{~d}$ & $\star$ \\
\hline
\end{tabular}

ANOVA: ${ }^{\star} \mathrm{p}=0.01$. Significant differences: $\mathrm{a} \& \mathrm{~b}, \mathrm{~b} \& \mathrm{c}, \mathrm{c} \& \mathrm{~d}$.

explanation met, $60 \%$ had their expectation of reassurance met, $61 \%$ had their expectation of advice met, and $73 \%$ had their expectation of help with making decisions met. Patient expectations and whether or not these were met were not predicted by any of the patient or counsellor variables measured.

Reporting receiving reassurance was found to be associated with a greater reduction in anxiety if it had been previously expected than if it had not. As in other areas of health care, it appears that identifying patient expectations and then meeting those expectations may lead to better outcomes of the consultation than providing a consultation that is not aimed at meeting patient expectations. This is consistent with the contrast theory of patient satisfaction, which postulates that performance that is higher than expected will be judged satisfactory, whereas performance that is less than expected will be judged unsatisfactory. ${ }^{20}$

Despite the ethos among genetic counsellors that they should not give advice, ${ }^{17-19} 50 \%$ of the study sample expected advice. Fifty percent of these reported having received advice. This is consistent with the advice ratings of the consultation transcripts, which found a mean of 5.8 advice statements per consultation. ${ }^{21}$ Those reporting receiving advice experienced a greater decrease in anxiety after the consultation than those not receiving advice. This raises 
the question of what type of advice patients are expecting and what type of advice genetic counsellors think they should not give. The word "advice" may be being used differently by genetic counsellors than by patients. More research is needed about the process and outcome of advice giving in genetic counselling.

It should be noted that expectations were determined by responses to a set of options and were not asked about in an open ended way. The response options were based on what genetic counsellors say they aim to provide. ${ }^{1}$ If patient expectations are elicited that are judged to be unrealistic or inappropriate, the counsellor may achieve better outcomes by altering these expectations than by not meeting them. This, however, is an empirical question. The questions of what expectations are appropriate and whether there is consensus about this are also ones that require further study.

The current study did not have the power to identify predictors of patient expectations or predictors of the meeting of expectations. This is an area in which more research is needed in order to develop our ideas about how to improve the meeting of patient expectations in genetic counselling. Such research should be guided by models and theories of patient satisfaction if we are to explain, as well as describe, the effects of meeting patient expectations. ${ }^{82}$

This research was funded by a programme grant from The Wellcome Trust. Theresa Marteau and Susan Michie are supported by The Wellcome Trust.

1 Fraser FC. Genetic counseling. Am f Hum Genet 1974;26:636-59.

2 Kessler S, Jacopini AG. Psychological aspects of genetic counseling. II. Quantitative analysis of a transcript of a genetic counseling session. Am F Med Genet 1982;12:421-
3 Lippman-Hand A, Fraser FC. Genetic counseling: provision and reception of information. Am F Med Genet 1979;3: 113-27.

4 Sorenson JR, Swazey JP, Scotch NA. Reproductive pasts, reproductive futures: genetic counseling and its effectiveness. New York: Alan R Liss, 1981.

5 Bosk CL. All God's mistakes: genetic counseling in a pediatric hospital. London: University of Chicago Press, 1992.

6 Kessler S. Current psychological issues in genetic counseling. F Psychosom Obstet Gynecol 1990;11:5-18.

7 Pascoe GC. Patient satisfaction in primary health care: a literature review and analysis. Evaluation and Programme Planning 1983;6:185-210.

8 Strasser S, Aharony L, Greenberger D. The patient satisfaction process; moving toward a comprehensive model. Med Care Rev 1993;50:219-48.

9 Koehler WF, Fottler MD, Swan JE. Physician-patient satisfaction: equity in the health services encounter. Med satisfaction: equity in the
Care Rev 1992;49:455-84.

10 Campion PD, Butler NM, Cox AD. Principle agendas of doctors and patients in general practice consultations. Fam Pract 1992;9:181-90

11 Korsch BM, Negrete VF. Doctor-patient communication. Sci Am 1972;227:66-74.

12 Henbest RJ, Stewart M. Patient-centredness in the consultation. 2. Does it really make a difference? Fam Pract 1990; 7:28-33.

13 Blanchard CG, Labrecque MS, Ruckdeschel JC, Blanchard EB. Physician behaviors, patient perceptions, and patient characteristics as predictors of satisfaction of hospitalized adult cancer patients. Cancer 1990;65:186-92.

14 Marteau TM, Bekker H. The development of a six-item short-form of the state scale of the Spielberger state-trait anxiety inventory (STAI). Brf Clin Psychol 1992:31:301-6.

15 Spielberger CD, Gorsuch RL, Lushene RE. The state trait anxiety inventory. Palo Alto, CA: Consulting Psychologists anxiety inventor.

16 Landis JR, Koch GG. The measurement of observer agreement for categorical data. Biometrics 1977;33:159-74

17 Clarke A. Genetics, ethics and audit. Lancet 1990;335:1145-

18 Clarke A. Is non-directive counselling possible? Lancet 1991;338:998-1001.

19 Harper PS. Practical genetic counselling. Oxford: ButterworthHeinmannn Ltd, 1988.

20 Sherif M, Hovland CI. Social judgment: assimilation and contrast effects in communication and attitude change. New Haven, CN: Yale University Press, 1961.

21 Michie S, Bron F, Bobrow M, Marteau T. Nondirectiveness in genetic counselling: an empirical study. $\mathrm{Am}$ f Hum Genet 1997;60:40-7.

22 Miller JA. Studying satisfaction, modifying models, eliciting expectations, posing problems, and making meaningful measurements. In: Hunt $\mathrm{HK}$, ed. Conceptualisation and measurement of consumer satisfaction and dissatisfaction. Cambridge, MA.: Marketing Science Institute, 1977. 